\title{
Monitoring of the Presence of Professional Expert Communities in the Russian Federation and Assessment of their Participation in the Development of the National Competence System
}

\author{
Ruslan Dolzhenko ${ }^{1}$, Svetlana Dolzhenko ${ }^{2}$, Aleksandr Nazarov $^{2}$, and Aleksandra Fedorenko ${ }^{2}$ \\ ${ }^{1}$ Ural Institute of Management, Branch of Russian Presidential Academy of National Economy and \\ Public Administration, 8 March St., 66, 620144 Ekaterinburg, Russia \\ ${ }^{2}$ Ural State University of Economics, 8 March St., 62, 620144 Ekaterinburg, Russia
}

\begin{abstract}
The article deals with the results of monitoring of the presence of professional expert communities in the Russian Federation, which have a particular impact on addressing socio-economic issues, including promoting the development of the national qualifications system in the country. The theoretical and methodological basis of the study is a criterial disclosure of the activities of expert communities based on the structure of the National Qualifications System. The study was carried out in 2020 and is a continuation of the previous works by the authors, implemented in 2016-2019, whose purpose was to monitor communities in a separate area of professional activity - personnel management. This study involved 56 communities, which were selected based on the participation of their representatives in one of ten Councils for Professional Competence $(25 \%$ of all Councils currently operating in the Russian Federation). The results may be of interest to representatives of the institutions of the National Competence System, as well as the education system in the context of the influence of trade communities on the content of educational programs through professional standards created by community representatives, and to the professional expert communities themselves.
\end{abstract}

\section{Introduction}

The relevance of the study is due to the increase and concretization of the role of professional expert communities (PEC) in the formation of the qualifications system and the translation of products produced by the structures of the national qualification system, educational institutions and industry practices.

The objective of the research is to monitor the presence of professional expert communities in the Russian Federation and assess their participation in promoting the development of individual elements of the national competence system (NCS).

The research tasks are: 
- a theoretical overview of the conceptual apparatus of the PEC, as well as the main elements of the NCS;

- formation of a sample of PEC according to the conceptual apparatus and considering the formulated criteria for referring communities to PEC;

- monitoring of the presence of PEC in the Russian Federation and identifying the proportion of communities that are actively involved in the development of the education system, the national competence system;

- assessment of the compliance of the studied communities with the PEC developed criteria.

The authors of the study point out the following as the main hypothesis: for PEC, actively interacting with representatives of the NCS and promoting the development of individual elements of the NCS, there is a high level of maturity and expertise, as well as the presence of non-commercial expert activities aimed at standardizing and quality control of professional competencies of community members.

\section{A Theoretical Overview of the Essence of Professional Expert Communities and Their Role in Promoting the Development of NCS Elements}

Based on the author's and foreign research [1-2], we shall clarify the essence of PEC as a self-organizing voluntary association of people based on interests and expertise (a combination of knowledge and experience) in a specific area of professional activity, carrying out regular communications aimed at self-development and searching for more effective approaches to solve professional problems both at the local level and at the level of the region, industry, state. The expert of the community will be considered a representative of the community with professional experience, as well as the necessary special knowledge and authority in the professional environment, implementing successful projects in the field of professional activities of the community, and also involved in solving social issues.

We should note that experts from professional communities also participate in the development of professional standards, which fundamentally distinguishes them from ordinary experts [3]. In this sense, PECs by their existence have formed a special layer of communities that are simultaneously carriers of both professionalism and expertise.

One of the key areas of application of the expert efforts of PEC is participation in the formation and development of NCS elements. The first publications related to NCS in Russia can be attributed to 2006, when a group of researchers [4] reviewed the principles and procedures for developing a national qualifications framework. At present, the experience is being refined and updated [5-7]. The period since 2006 has been marked by phased steps in the formation of NCS. The National Council for Professional Competence under the President of the Russian Federation (the National Council), created by Decree No. 249 of April 16, 2014, becomes a single platform that ensures the development of NCS in our country. The creation of the National Council triggers professional communities to show their role and expert participation in the development of the NCS. Our analysis of the composition of the National Council shows that at present, the largest share in the Council is occupied by representatives of non-profit associations and the smallest - by the education system (Fig. 1). 


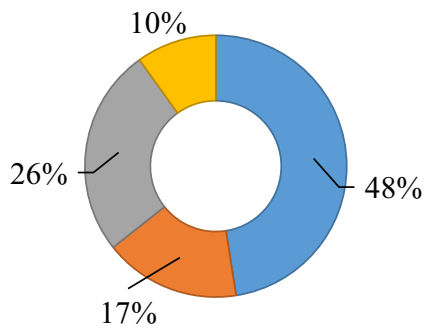

$\square$ Non-profit organizations

$\square$ Business

$\square$ Power

$\square$ Education

Fig. 1. The structure of representation of government institutions, social institutions of education, science, civil society in the National Council under the President of the Russian Federation for professional competence [14]

Note that $95 \%$ of the non-profit associations present in the National Council belong to any community (Fig. 2). At the same time, the largest share (40\%) is occupied by various sectoral and cross-sectoral professional communities, which play a special role of these communities in decision-making related to the development of individual elements of NCS. In terms of the tasks of our study, these communities are of greatest interest to us.

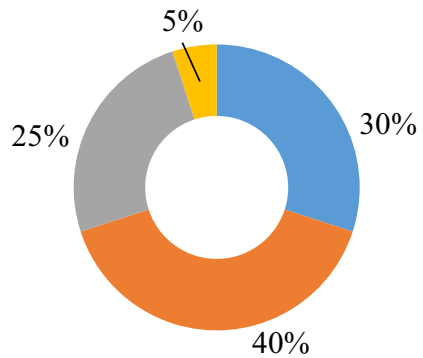

\author{
Business community \\ Sectoral and cross-sectoral \\ trade associations \\ Trade unions \\ Other non-profit organizations
}

Fig. 2. The structure of representation of community types in non-profit organizations that are members of the National Council for Professional Competence under the President of the Russian Federation [14]

To further analyze the role of professional expert communities in the development of NCS in Russia, let us consider the main elements of NCS [4].

One of the key elements of NCS is professional standards in professional activity, as well as the procedure for recognizing professional standards. A meaningful analysis of regulatory legal acts $[15,16,17]$ carried out by the authors of the study made it possible to identify the mention of PEC in these regulatory documents and the regulation of their participation in the development of professional standards, as well as professional-public discussion and examination of draft professional standards:

Institutional, organizational, and methodological mechanisms for the development and implementation of national and regional policies in competencies are also referred to the elements of NCS, including the National Council for Professional Competence under the President of the Russian Federation, the Ministry of Labor and Social Protection of the Russian Federation, the National Agency for the Development of Competence (NADC), Councils for Vocational Competencies (CVC).

Let us dwell in more detail on the CVC activities as a key, permanently operating body of NCS. PEC within the established powers of CVC can monitor the labor market; develop, apply and update professional standards, industry qualifications frameworks and qualifications requirements; organize and coordinate activities for the independent 
assessment of qualifications; participate in the development of state standards for vocational education, update vocational education and training programs, incl. through professional public accreditation. Currently, there are 39 CVCs operating in Russia.

Another important element of NCS for our research is the system of quality assurance of competencies through the implementation of an independent assessment of competencies (IAC). Professional communities are also directly involved in the implementation of this element of NCS, including in the development of assessment tools for the relevant qualifications used by the qualification assessment centers during the professional examination, and as experts at the professional exams of the IAC, during which the qualification assessment center, with the participation of experts, assesses the professional qualifications of the applicant for compliance with the provisions of the professional standard.

Thus, the interest of the PEC representatives in supporting and developing the NCS elements is due to the following reasons:

- the emergence of transparent indicators for assessing the competence level of candidates when implementing the procedure for selecting and assessing the competencies of existing employees;

- the ability to identify inconsistencies with the required level of qualifications, determine training needs; reasonable planning of personnel development procedures based on determining and trajectories of obtaining the required competencies;

- the emergence of an open source of information on competencies, quality assurance mechanisms, ways of effective interaction with educational institutions, which make it possible to more clearly formulate the needs and expectations of business from training programs.

A theoretical analysis of the conceptual apparatus of professional expert communities, as well as NCS elements, allows us to draw the following conclusion: the awareness of the institutional role of the NCS in matters of standardization and assessment of the professional qualifications of representatives of trade communities increases the level of community involvement in interaction with individual NCS institutions.

\section{Methods of PEC Monitoring and Assessment of Factors that Determine Involvement in the Formation and Development of NCS Elements}

The content of the NCS elements and the main options for remuneration (including intangible) of the participants of the NSC allow for a criterial, parametric analysis to identify the NSC and assess their involvement in activities associated with the operation of the NSC. For us, such blocks as self-presentation of the community as an expert, institutionalization of the community as an organization, and the declaration of certain types of activities are essential. Table 1 shows the criteria and assessment parameters developed by us. We also use content analysis of published information on the types of PEC activities for identifying the activity of communities and combining them into semantic groups (directions).

Table 1. Criteria of professional expert communities and parameters of their identification based on information from open sources

\begin{tabular}{|l|l|}
\hline PEC status identifying criteria & \multicolumn{1}{|c|}{ Parameters of compliance with a given criterion } \\
\hline $\begin{array}{l}\text { Criterion 1: There is a } \\
\text { professional group that presents } \\
\text { itself as a trade community }\end{array}$ & $\begin{array}{l}\text { The use in the descriptive characteristics of the community of } \\
\text { concepts corresponding to the semantic units: trade } \\
\text { community/union/association/association/partnership). }\end{array}$ \\
\hline
\end{tabular}


Continuation of Table 1.

\begin{tabular}{|l|l|}
\hline \multicolumn{1}{|c|}{ PEC status identifying criteria } & \multicolumn{1}{|c|}{ Parameters of compliance with a given criterion } \\
\hline $\begin{array}{l}\text { Criterion 2: There is a formal } \\
\text { institution for the maintenance } \\
\text { and development of community } \\
\text { activities }\end{array}$ & $\begin{array}{l}\text { The community is institutionalized, or is at the final stage of } \\
\text { institutionalization (the presence of elements of } \\
\text { institutionalization is presented in Table 2) }\end{array}$ \\
\hline $\begin{array}{l}\text { Criterion 3: The community } \\
\text { positions itself as an expert }\end{array}$ & $\begin{array}{l}\text { The list of activities includes non-commercial expert } \\
\text { activities (community participation in the development of } \\
\text { professional standards, etc.) }\end{array}$ \\
\hline $\begin{array}{l}\text { Criterion 4: Community business } \\
\text { lines are also related to expertise }\end{array}$ & $\begin{array}{l}\text { The list of activities includes consulting, expertise, } \\
\text { assessment, carried out on a commercial basis with the } \\
\text { involvement of community members }\end{array}$ \\
\hline $\begin{array}{l}\text { Criterion 5: There is a selection to } \\
\text { the community and the quality } \\
\text { control of community members. }\end{array}$ & $\begin{array}{l}\text { The conditions for joining the community are described, } \\
\text { while the selection is based not only on payment for } \\
\text { participation in the community but also on the assessment of } \\
\text { the level of expertise of community members }\end{array}$ \\
\hline $\begin{array}{l}\text { Criterion 6: Community members } \\
\text { are recognized experts }\end{array}$ & $\begin{array}{l}\text { A register of community experts is provided. } \\
\text { The participation of community members as experts in the } \\
\text { work of public chambers and councils, CVC, etc. is } \\
\text { described. }\end{array}$ \\
\hline
\end{tabular}

It should be noted that at present neither scientific literature nor static reports provide summary data on professional communities operating in the Russian Federation. This work will use the term "trial monitoring" to emphasize that the study does not cover the entire possible framework of PEC in Russia but aimed at checking the viability of the monitoring methodology and identifying PEC, as well as determining the measure of their compliance with the proposed evaluation criteria. Trial monitoring included 56 PECs that meet at least four criteria presented in the table.

The information was obtained from open sources. The sampling was implicitly influenced by two more criteria, in addition to those stated in Table 4: these PECs have a specific form of representation on the Internet (a website or pages in social networks), and they are not in-house.

To identify "candidates" for the PEC, we proceeded from the assumption that they can be found either in the lists of CVC members, or in the lists of the developers of individual professional standards. The assumption met some limitations: SECs were created for not all spheres, not every sphere is differentiated and concretized, not every type of expert knowledge is reflected in SECs (for example, marketing, represented by a sufficient number of SECs); at the same time, SECs of the fuel and power complex are represented by manufacturing organizations, rather than organizations that can be called PEC in this area.

The study involved PECs in such areas of professional activity as personnel management, finance, hospitality, information technology, office activities, engineering surveys, urban planning and architectural and construction design, beauty industry, agroindustrial complex, health care, and electric power industry.

Another interesting point was the regional aspect. PEC can act as experts regardless of the administrative-territorial link, but those participating in the development of professional standards and the work of the CVC, systemically significant, are centralized in Moscow (or have a representative office there); in our monitoring, they account for $78.6 \%$.

Note that the number of PEC members is controversial for the calculation: the PEC members can be both individuals and legal entities. Here we found a range from 11 to 6,000 legal entities and from 18 to 500,000 individuals (in total over the years of existence). Information about the number was found in $42.9 \%$ of PECs. 


\section{PEC Monitoring Results}

The conversation about the number should be continued by differentiating into PEC members and singling out directly the experts of this community from their number. Only $19.6 \%$ of the reviewed PECs have provided the register of experts in open access. The number of experts, in general, does not exceed 100 people, with the exception of WorldSkills with 42,000 specialists as experts.

As the studied communities were created in 1885-2018 (information is indicated for $76.5 \%$ of PECs), and 2007 became the median value, it can be assumed that over the years of existence, the main features of PEC have been formed. However, we can see that not all are reflected in the portrait of communities.

PEC has $100 \%$ met the criterion for the use of concepts corresponding to keywords in the descriptive characteristics of the community.

According to the block of institutionalization criteria, we note a high degree of publicity. Community culture itself is the least represented.

Table 2. The share of references to the elements of PEC institutionalization

\begin{tabular}{|l|c|}
\hline \multicolumn{1}{|c|}{ Areas of non-commercial activity } & Share of references, \% \\
\hline There is a community leader & 91.1 \\
\hline There is an organizational arrangement & 91.1 \\
\hline There is a goal (and/or mission, ideology) & 89.3 \\
\hline There is a set of rules and regulations & 85.7 \\
\hline There is a distribution of roles, a hierarchy & 80.4 \\
\hline There is a formed community culture & 69.6 \\
\hline
\end{tabular}

We should note that $80.4 \%$ of PECs indicated the conditions for joining the community.

We cannot single out the relationship of community creation and its size to the time. Therefore, the issues of retransmission of the elements of institutionalization, including those affecting the recognition of the community, we leave within the boundaries of the organizational and marketing abilities and needs of the management structures of PEC.

We consider the indication of specific types or areas of activity as an extremely important criterion. $85.7 \%$ of PECs are engaged in non-commercial activities and $87.5 \%-$ in commercial. $80.4 \%$ of PECs combine both types of activity.

The results of the analysis of non-commercial activities (Table 3) show that participation in the development of professional standards and the work of PEC is within its interests; however, the community has also increased attention to research consulting and recommendation activities, the development of the service market. Note that even though we were guided by the composition of CVC when identifying the PEC, only a small share of the PEC notes participation in the work of the councils.

Table 3. Distribution of references to the directions of non-commercial activities of PEC

\begin{tabular}{|l|c|}
\hline \multicolumn{1}{|c|}{ Areas of non-commercial activity } & $\begin{array}{c}\text { Share of } \\
\text { references, \% }\end{array}$ \\
\hline Consultations, research, independent examination & 13.6 \\
\hline Development of professional standards & 13.6 \\
\hline Support and organization of socially significant projects & 12.0 \\
\hline $\begin{array}{l}\text { Development of the industry (service market), development of a } \\
\text { service quality standard, elaboration of professional ethics }\end{array}$ & 12.0 \\
\hline $\begin{array}{l}\text { Support and development of professional education (including } \\
\text { development and accreditation of educational programs) }\end{array}$ & 10.4 \\
\hline
\end{tabular}


Continuation of Table 3

\begin{tabular}{|l|c|}
\hline Areas of non-commercial activity & $\begin{array}{c}\text { Share of } \\
\text { references, \% }\end{array}$ \\
\hline $\begin{array}{l}\text { Information exchange, publication of materials, informational, } \\
\text { methodological and legal support }\end{array}$ & 8.8 \\
\hline $\begin{array}{l}\text { Interaction with authorities, discussion of public policy issues in a } \\
\text { specific area }\end{array}$ & 5.6 \\
\hline Promotion and popularization of the profession & 5.6 \\
\hline Improvement of the regulatory framework & 5.6 \\
\hline Participation in the work of CVC & 4.8 \\
\hline $\begin{array}{l}\text { Service market monitoring, control and identification of } \\
\text { unscrupulous participants }\end{array}$ & 3.2 \\
\hline Assistance in employment and other support to PEC members & 3.2 \\
\hline Dispute resolution & 1.6 \\
\hline
\end{tabular}

Analysis of the types of commercial activities (Table 4) shows its lower diversity and priority of training and assessment and qualification activities that rely on a credit of trust in experts.

Table 4. Distribution of references to the directions of commercial activities of PEC

\begin{tabular}{|l|c|}
\hline \multicolumn{1}{|c|}{ Areas of commercial activity } & $\begin{array}{c}\text { Share of } \\
\text { references, } \%\end{array}$ \\
\hline Training, professional development, schools and master classes & 36.1 \\
\hline Audit, examination, documentation, and other support & 16.7 \\
\hline Assessment of competencies, certification & 16.7 \\
\hline $\begin{array}{l}\text { Organization and verification of specialized events (including } \\
\text { competitions), publishing }\end{array}$ & 13.9 \\
\hline Professional and public accreditation & 6.9 \\
\hline Recruitment of personnel (specialists) & 4.4 \\
\hline Outsourcing, legal services & 4.2 \\
\hline Implementation of professional standards into practice & 1.4 \\
\hline
\end{tabular}

It is interesting that both non-commercial and commercial activities have mentioning of both examination and accreditation.

\section{Conclusions and Recommendations for the Development of PEC Research}

Thus, we have generally confirmed our hypothesis that professional expert communities that promote the development of individual elements of the NCS are characterized by a high level of maturity: only one community, represented in the monitoring, is valid for 2 years; the term of the rest is at least 5 years; the presence of basic elements of institutionalization is typical for more than $80 \%$ of PECs. Most of these communities show a high level of expertise, provided both due to restrictions on entering the community and the implementation of certain areas of expert activity, both commercial and noncommercial.

At the same time, it is worth noting points of growth for the development of interaction between the PEC and the NCS institutes in such areas as the development of professional standards, control and assessment tools, and labor market monitoring. These areas are in the 
focus of CVC, while, as the monitoring showed, even those PECs that are part of the CVC have not yet fully implemented the listed expert activities, for example, only $13.6 \%$ of communities are engaged in the development of professional standards. The identified problems require further research.

In particular, the above leads to the need for in-depth interviews with the PEC leaders on a number of topics, including the discussion of the mechanisms for embedding the PEC in the implementation of socially significant tasks of the region and the country. As the non-profit activity of communities is quite widespread as a practice, and is close to volunteer in its type, additional attention should be paid to the study of the motivation of PEC participants to such activity. The analysis of respondents' answers can be carried out considering the existing research on the motivation of volunteers and experts [8-13].

\section{Acknowledgments}

The article is financially supported by the Russian Foundation for Basic Research within the framework of scientific project No. 19-010-00933 "Socio-economic foundations for the development and institutionalization of professional expert communities". The authors of the study would like to thank the professional communities for their help in monitoring: Community HUB, "Association of Managers and Specialists in Human Resource Management" SRSO.

\section{References}

1. R.A. Dolzhenko, S.B. Dolzhenko, Herald of Omsk University. Series «ECONOMICS», 3, 78 (2019)

2. W.J. Goode, American sociological review, 22(2), 194 (1957)

3. R.A. Dolzhenko, Problems of economics and management of the oil and gas complex, 1, 34 (2015)

4. A.A. Murav'eva, O.N. Oleynikova, M. Coles, Principles and procedures for developing a national qualifications framework (2006)

5. N. Pilcher, S. Fernie, K. Smith, Journal of education and work, 30(1), 1 (2017)

6. S. Allais, Journal of education and work, 30(7), 768 (2017)

7. B. Mikulec, European educational research journal,16, 455 (2017)

8. E.G. Clary, M. Snyder, R.D. Ridge et al., Journal of personality and social psychology, 74(6), 1516 (1998)

9. H. Bussell, D. Forbes, International journal of nonprofit and voluntary sector marketing, 7(3), 244 (2002)

10. J. Osborne, S. Collins, M. Ratcliffe, R. Millar, R. Duschl, JRST, 40(7), 692 (2003)

11. J. Settlage, School science and mathematics, 104(5), 214 (2004)

12. J. Wübbeke, Journal of contemporary China, 22:82, 712 (2013)

13. Á. Blanco-López, E. España-Ramos, F.J. González-García, A.J. Franco-Mariscal, JRST, 52(2), 164 (2015)

14. Official website of the National Council, http://nspkrf.ru/sostav-soveta.html

15. Decree of the Government of the Russian Federation No. 23 of January 22, 2013, "On the rules for the development and approval of professional standards"

16. Order of the Ministry of Labor of Russia No. 170n dated April 29, 2013, "On the approval of guidelines for the development of a professional standard" 
17. Order of the Ministry of Labor of Russia No. 671n dated September 30, 2014, "On the approval of guidelines for organizing professional and public discussion and examination of draft professional standards" 